\title{
DO QUE ADOECEM E POR QUE SE AFASTAM DO TRABALHAM DIFERENTES TRABALHADORES DE UMA UNIVERSIDADE: ANÁLISE DO ANO DE 2009
}

\author{
Fátima Neves do Amaral COSTA* \\ Lis Maria Benassi CÉZAR* \\ Cássia Tiêmi Nagasawa EBISUI ${ }^{* * *}$
}

RESUMO: Trata-se de um estudo, de natureza quantitativa, que avaliou no ano de 2009, o fato de que ficaram, durante aquele período, afastados do trabalho diferentes trabalhadores que atuavam em quatro unidades de uma universidade pública no interior de São Paulo, assim como a causa da doença que provocou este afastamento. Do quadro trabalhado, que envolveu local de trabalho, funçóes desempenhadas e período de afastamento, pode-se afirmar que, homens e mulheres, que se afastaram do trabalho, por um tempo maior, tinham suas atribuiçóes preferencialmente ligadas a serviços repetitivos. Foi possível identificar também que as morbidades prevalentes relacionaram-se aos transtornos mentais seguidos de doenças do sistema osteomuscular e do tecido conjuntivo. Tais achados impulsionam necessários aprofundamentos teóricos sobre as condiçóes dos ambientes de trabalho onde se encontram esses trabalhadores, assim como o grau de satisfação dos mesmos, para identificar e prevenir aspectos geradores

\footnotetext{
* UNESP - Universidade Estadual Paulista. Faculdade de Ciências e Letras Departamento de Didática. Araraquara - SP - Brasil. 14800-000 - fnacosta@fclar.unesp.br.

** Supervisora. UNESP - Universidade Estadual Paulista.Seção Técnica de Saúde. Araraquara - SP - Brasil. 14800-000 - fnacosta@fclar.unesp.br.

*** Coordenadora Pedagógica. ETEC "Profa. Anna de Oliveira Ferraz" - Centro Estadual de Educação Tecnológica Paula Souza.Araraquara - SP - Brasil. 14801-180 - cassia.tne@gmail.com.
} 
de conflitos, pressóes e sofrimento no local de trabalho, que poderão desencadear doenças.

PALAVRAS-CHAVE: Trabalho. Trabalhador. Adoecimento. Prevenção.

\section{Introdução}

Entre os determinantes da saúde do trabalhador podemos elencar os condicionantes sociais, econômicos, tecnológicos e organizacionais responsáveis pelas condiçóes de vida e os fatores de riscos presentes nos processos de trabalho (BRASIL, 2001).

Por outro lado, na atualidade, cresce em importância também a valorização dos aspectos positivos e promotores de saúde presentes no trabalho. Trabalho que será aqui considerado, como um saber fazer que mobiliza a intencionalidade, a capacidade de refletir, reagir, sentir, criar. Náo se toma aqui o trabalho, exclusivamente, como emprego, mas como uma forma de inserção e colaboração na sociedade. Um trabalho que é realizado em um ambiente, que, se assumido enquanto gratificante, poderá estar associado ao bem estar e levar o profissional a se satisfazer com o produto de seu trabalho, ou de outro modo, será produzido dor e sofrimento. Assim, em função de suas exigências e pressóes, o trabalho poderá ocasionar doença. $\mathrm{O}$ reconhecimento do contexto do trabalho na determinaçáo e ocorrência de doenças será trabalhado neste artigo através do referencial dejouriano (DEJOURS, 1993, 1994, 2003).

A Constituiçáao Brasileira de 1988 (BRASIL, 1988), em seu artigo 196, determina que saúde é direito de todos e dever do Estado. Tal direito deve ser garantido mediante políticas sociais e econômicas que visem tanto à redução do risco da doença e de outros agravos, como ao acesso universal e igualitário às açôes e serviços, para a sua promoção e recuperação. A mesma Constituição prevê o direito a um ambiente de trabalho saudável. Contudo, a efetivação dessa prerrogativa ainda náo foi conquistada. Além disso, não preconiza determinaçóes preventivas sobre o ambiente de trabalho dos trabalhadores como forma de minimizar os problemas de saúde. Além da Constituição Federal, outros instrumentos e regulamentos federais e 
internacionais orientam o desenvolvimento das açóes no campo da saúde do trabalhador.

A operacionalização das atividades deve ocorrer nos planos nacional, estadual, municipal (BRASIL, 1998a, 1998b; Convenção/OIT $\mathrm{n}^{\circ}$ 155/1981-ratificado pelo Brasil em 1998). Nesse contexto, tomar conhecimento do que adoece uma população de trabalhadores, e por que se afastam do trabalho, poderia sugerir contribuiçóes significativas a serem consideradas em um Programa de Atenção à Saúde do Trabalhador.

O objetivo deste artigo é apresentar um panorama de afastamentos dos servidores do seu trabalho em 2009, particularmente, destacando-se licenças médicas e suas causas em quatro unidades de uma Universidade no interior do Estado de São Paulo.

\section{Metodologia}

Os dados foram coletados inicialmente a partir das análises individuais de prontuários dos funcionários que se afastaram do trabalho por licença médica no decorrer de 2009. Foram mapeados os dados por meio de estatística descritiva ${ }^{*}$. As associaçóes de interesse foram estudadas utilizando-se o teste qui-quadrado $\left(\mathrm{X}^{2}\right)$. O nível de significância adotado foi de 5\%. Destacaram-se as categorias abaixo descritas que caracterizavam:
a. Atividade Funcional.
b. Funcionários (periciados), unidade e solicitação de afastamento.
c. Funcionários(periciados), unidade e dias de afastamento.
d. Funcionários(periciados) e CID-10
e. CID-10-

Num outro momento, buscamos relaçóes entre tais dados que pudessem auxiliar na compreensão dos motivos do afastamento. Os resultados foram analisados confrontando-se com os referenciais teóricos utilizados neste estudo. 


\section{Resultados e discussáo}

Tabela 1 - Distribuição dos servidores segundo sexo. Janeiro - Dezembro, 2009.

\begin{tabular}{lcc}
\hline Sexo & $\mathbf{n}$ & $\mathbf{\%}$ \\
\hline masculino & 105 & 47,73 \\
feminino & 115 & 52,27 \\
\hline Total & 220 & 100,00 \\
\hline
\end{tabular}

Fonte: Elaboração própria.

Tabela 2 - Distribuição dos servidores segundo dias de afastamento em cada sexo. Janeiro - Dezembro, 2009.

\begin{tabular}{llc}
\hline Sexo & média \pm desvio-padrão & $\mathbf{p}^{\S}$ \\
\hline Masculino & $47,23 \pm 39,43$ & \\
Feminino & $51,16 \pm 38,29$ & $<0,454$ \\
\hline$\S_{\text {teste t Student }}$ & &
\end{tabular}

Fonte: Elaboração própria.

As tabelas 1 e 2 não evidenciaram diferenças significativas entre homens e mulheres que se afastaram do trabalho. Esse dado é importante, pois revela que, na atualidade, também os homens estão buscando caminhos para o enfrentamento das questóes pessoais de saúde. Revela também que o serviço que os atende lhe garante esse cuidado, fato que vai consolidando uma mentalidade de Educação em Saúde não apenas direcionada para a saúde da mulher e suas especificidades.

Medidas voltadas a exames médicos no campo da Atenção Primária à Saúde com tudo o que nela comportam são realizadas rotineiramente junto aos servidores, através da Seção responsável pela Atenção à Saúde.

A partir do ano de 2001, além do enfoque preventivo, tal seção, por meio do Programa Geral de Saúde e Segurança do Trabalhador, ampliou a sua atenção ao servidor, oferecendo também os cuidados nos campos da promoção e recuperação da saúde. 
Do que adoecem e por que se afastam do trabalham diferentes trabalhadores de uma universidade: análise do ano de 2009

Tabela 3 - Distribuição dos servidores afastados segundo atividade funcional. Janeiro - Dezembro, 2009.

\begin{tabular}{|c|c|c|}
\hline Atividade funcional & $\mathbf{n}$ & $\%$ \\
\hline agente de telefonia e recepção & 10 & 4,55 \\
\hline agente de vigilância e recepção & 14 & 6.36 \\
\hline assistente administrativo & 18 & 8,18 \\
\hline assistente de informática & 3 & 1,36 \\
\hline assistente operacional & 81 & 36.82 \\
\hline assistente serviço documentação e pesquisa & 8 & 3,63 \\
\hline assistente social & 4 & 1,82 \\
\hline assistente de suporte acadêmico & 18 & 8,18 \\
\hline assistente técnico administrativo & 3 & 1,36 \\
\hline auxiliar docente & 2 & 0,91 \\
\hline bibliotecário & 7 & 3.18 \\
\hline cozinheira & 1 & 0,45 \\
\hline desenhista & 1 & 0,45 \\
\hline docente & 18 & 8,18 \\
\hline medico & 4 & 1,82 \\
\hline motorista & 18 & 8,18 \\
\hline oficial administração universitária & 1 & 0,45 \\
\hline operador de máquinas & 4 & 1,82 \\
\hline químico & 1 & 0,45 \\
\hline técnico de laboratório & 4 & 1,82 \\
\hline Total & 220 & 100,00 \\
\hline
\end{tabular}

Fonte: Elaboração própria.

Observou-se que a maior demanda de afastamentos provém de servidores técnico- administrativos na função de assistente operacional. 
Tabela 4 - Distribuição dos servidores segundo atividade funcional. Janeiro - Dezembro, 2009.

\begin{tabular}{lcccc}
\hline & \multicolumn{2}{c}{ Afastamento } & & \\
Unidade & Sim & Não & Total & p§ \\
\hline Docente & 18 & 387 & 405 & \\
Técnico Administrativo & 202 & 490 & 692 & \\
\hline Total & 220 & 877 & 1097 & $<0,001^{*}$ \\
\hline
\end{tabular}

${ }^{\S}$ Teste de qui-quadrado; *diferença estatisticamente significativa.

Fonte: Elaboração própria.

As tabelas 3 e 4 revelaram que os servidores mais comprometidos pela saúde, fato que exigiu maiores afastamentos e licenças, são aqueles ligados a áreas técnicas, que menos controle, criatividade, autonomia tem sob seu próprio trabalho. Esse dado é confirmado em textos clássicos sobre as relaçóes entre organização do trabalho e danos à saúde: "Via de regra, mais a divisão do trabalho é acentuada, menor o conteúdo significativo do trabalho e menores são as possibilidades de mudá-lo, maiores são os sofrimentos do trabalhador". (DEJOURS, 2003, p.48).

Tabela 5 - Distribuição dos servidores segundo unidade e solicitação de afastamento. UNESP, STS, Janeiro - Dezembro, 2009.

\begin{tabular}{lcccc}
\hline \multicolumn{5}{c}{ Afastamento } \\
Unidade & Sim & Não & Total & $\mathbf{p}^{\S}$ \\
\hline A & 62 & 182 & 244 & \\
B & 87 & 269 & 356 & \\
C & 29 & 257 & 286 & \\
D & 42 & 169 & 211 & \\
\hline Total & 220 & 877 & 1097 & $<0,001^{*}$ \\
\hline
\end{tabular}

${ }^{5}$ Teste de qui-quadrado; *diferença estatisticamente significativa

Fonte: Elaboração própria. 
Nota-se número de afastamento significativamente menor entre os servidores das Unidades $\mathrm{C}$ e D e significativamente maior entre os servidores das Unidades A e B.

Os servidores se afastaram em média 49,28 $\pm 38,80$ dias do trabalho. A distribuição dos servidores segundo número médio de dias de afastamento em cada unidadeencontra-se na Tabela 6.

Tabela 6 - Distribuição dos servidores segundo dias de afastamentos em cada unidade. Janeiro - Dezembro, 2009.

\begin{tabular}{lll}
\hline Unidade UNESP & média \pm desvio-padrão & $\mathbf{p}^{\S}$ \\
\hline A & $61,00 \pm 36,46^{\mathrm{a}}$ & \\
B & $52,28 \pm 38,55^{\mathrm{a}}$ & \\
C & $54,52 \pm 39,39^{\mathrm{a}}$ & \\
D & $27,29 \pm 32,45^{\mathrm{b}}$ & $<0,001^{*}$ \\
\hline
\end{tabular}

${ }^{\$}$ Análise de Variância; *diferença estatisticamente significativa; ${ }^{\text {a,b }}$ letras iguais indicam similaridade estatística

Fonte: Elaboração própria.

Os servidores da unidade $\mathrm{D}$ requereram menor tempo de afastamento $(\mathrm{p}<0,001)$ que aqueles de outras unidades.

As tabelas 5 e 6 indicam que os afastamentos ocorreram em maior número de solicitaçôes e maior número de dias entre os servidores das unidades A e B ao passo que os servidores da unidade D desfrutam de menor tempo de afastamento.

Pinheiro (2004)discute as possíveis características de um ambiente preventivo de problemas da saúde do trabalho dentre elas: o respeito; reconhecimento; garantia de privacidade; tolerância aos conflitos; busca de reconciliação; sentido de comunidade; empatia.

A adoção de uma abordagem preventiva representaria um investimento prudente no futuro da Instituição, pois, inicialmente, apresentaria o envolvimento positivo no trabalho e reduziria prolongados dias de licenças e afastamentos. (PINHEIRO, 2004). 
Fátima Neves do Amaral Costa,

Lis Maria Benassi Cézar e Cássia Tiêmi Nagasawa Ebisui

Tabela 7 - Distribuição dos servidores segundo CID-10. Janeiro - Dezembro, 2009. (Anexo pag.16)

\begin{tabular}{|c|c|c|}
\hline CID-10 & $\mathrm{n}$ & $\%$ \\
\hline A & 2 & 0,92 \\
\hline B & 8 & 3,67 \\
\hline $\mathrm{C}$ & 5 & 2,29 \\
\hline $\mathrm{C} / \mathrm{K}$ & 4 & 1,83 \\
\hline D & 4 & 1,83 \\
\hline $\mathrm{E} / \mathrm{I}$ & 1 & 0,46 \\
\hline $\mathrm{F}$ & 53 & 24,31 \\
\hline $\mathrm{F} / \mathrm{G}$ & 4 & 1,83 \\
\hline $\mathrm{F} / \mathrm{M}$ & 3 & 1,38 \\
\hline G & 7 & 3,21 \\
\hline G/D & 1 & 0,46 \\
\hline $\mathrm{G} / \mathrm{F}$ & 1 & 0,46 \\
\hline $\mathrm{G} / \mathrm{F} / \mathrm{E}$ & 3 & 1,38 \\
\hline $\mathrm{G} / \mathrm{M}$ & 1 & 0,46 \\
\hline $\mathrm{G} / \mathrm{M} / \mathrm{F}$ & 3 & 1,38 \\
\hline $\mathrm{H}$ & 10 & 4,59 \\
\hline $\mathrm{H} / \mathrm{Z}$ & 1 & 0,46 \\
\hline I & 18 & 8,26 \\
\hline $\mathrm{I} / \mathrm{C} / \mathrm{Z}$ & 1 & 0,46 \\
\hline $\mathrm{I} / \mathrm{E}$ & 3 & 1,38 \\
\hline $\mathrm{I} / \mathrm{E} / \mathrm{F}$ & 1 & 0,46 \\
\hline $\mathrm{J}$ & 8 & 3,67 \\
\hline K & 1 & 0,46 \\
\hline $\mathrm{K} / \mathrm{F}$ & 2 & 0,92 \\
\hline $\mathrm{L} / \mathrm{G}$ & 1 & 0,46 \\
\hline M & 31 & 14,22 \\
\hline $\mathrm{M} / \mathrm{F}$ & 1 & 0,46 \\
\hline $\mathrm{M} / \mathrm{G}$ & 5 & 2,29 \\
\hline $\mathrm{N}$ & 3 & 1,38 \\
\hline $\mathrm{N} / \mathrm{E}$ & 2 & 0,92 \\
\hline $\mathrm{R}$ & 2 & 0,92 \\
\hline S & 20 & 9,17 \\
\hline $\mathrm{S} / \mathrm{F}$ & 1 & 0,46 \\
\hline $\mathrm{S} / \mathrm{G} / \mathrm{M}$ & 1 & 0,46 \\
\hline $\mathrm{T}$ & 6 & 2,75 \\
\hline W & 1 & 0,46 \\
\hline Z & 1 & 0,46 \\
\hline Total & 220 & 100,00 \\
\hline
\end{tabular}

Fonte: Elaboração própria. 
Observa-se alta prevalência de indivíduos com CID-10 classificado como $\mathbf{F}$ o que caracteriza Transtornos Mentais e Comportamentais, seguido do CID-10 M referente às Doenças do Sistema Osteomuscular e do Tecido Conjuntivo .

A análise da tabela 7 revela a distribuição dos servidores segundo CID-10. Torna-se visível à prevalência dos indivíduos portadores de transtornos mentais e comportamentais, seguido daqueles indivíduos que apresentam doenças do sistema osteomuscular e do tecido conjuntivo.

Tratando inicialmente da prevalência dos portadores de transtornos mentais, segundo estimativa da OMS, os transtornos mentais acometem cerca de $30 \%$ dos trabalhadores e os transtornos mentais graves, cerca de 5 a $10 \%$.

No Brasil, dados do INSS sobre a concessão de benefícios previdenciários, de auxílio à doença, por incapacidade para o trabalho superior a 15 dias e de aposentadoria por invalidez, por incapacidade definitiva para o trabalho, mostram que os transtornos mentais, ocupam o terceiro lugar entre as causas dessas ocorrências (BRASIL, 2001).

O processo de comunicação no ambiente de trabalho moldado pela cultura organizacional é considerado fator importante na determinação da saúde mental. Ambientes que impossibilitam a comunicação espontânea, a manifestação de insatisfaçóes e as sugestóes dos trabalhadores poderão provocar sofrimentos e distúrbios mentais. (MASLACH; LEITTER, 1999)

Trazendo para o presente as discussóes das Doenças do Sistema Osteomuscular e do Tecido Conjuntivo, tem-se que os trabalhadores compartilham os perfis de adoecimento e morte da população em geral, em função de sua idade, gênero, grupo social ou inserção em um grupo específico de risco. Além disso, os trabalhadores podem adoecer ou morrer por causas relacionadas ao trabalho. Acontece com as doenças desse grupo, que tem o seu desenvolvimento ampliado ou tornado mais complexo pelo trabalho. A decisão quanto à existência de relação causal entre a doença diagnosticada ou suspeita e uma situação de trabalho é considerada por especialistas como processo social. A comprovação dessa relaçáo deve basear-se em argumentos que permitam a sua presunção, sem a existência de prova absoluta (BRASIL, 2001). 
No conjunto das tabelas vale destacar, que apesar dos "dados" serem aparentemente "diferentes", especialistas alertam para o fato de que o aumento de prevalência de doenças como as lesóes por esforço repetitivo; fibromialgias, e o surgimento de novas formas de adoecimento mal caracterizadas como estresse, fadiga física e mental configuram situaçóes que exigem mais pesquisa e conhecimentos, a fim de se caminhar para intervençôes mais efetivas que ultrapassem a prescrição de licenças de saúde como resoluçáo de problemas.

\section{Consideraçóes finais}

Este estudo teve como objetivo apresentar um panorama do perfil de adoecimento que motivou os afastamentos dos funcionários de quatro unidades de uma universidade no interior do Estado de São Paulo, no ano de 2009. Princípios teóricos sobre o campo da saúde do trabalhador foram discutidos contrapondo-se com os dados quantitativos obtidos. De maneira geral, pode-se dizer que no quadro trabalhado (local de trabalho, funçóes), os servidores que se afastaram do trabalho foram homens e mulheres; preferencialmente ligados a serviços com menor exigência intelectual. Destacou-se que duas unidades apresentaram representatividade mais significativa de afastamentos entre seus servidores.

De modo esquemático, é possível afirmar que o perfil de morbidade dos servidores afastados caracterizou-se pela existência de agravos ligados aos Transtornos Mentais seguidos das doenças do Sistema Osteomuscular e do Tecido Conjuntivo. Tais informaçóes, focadas, no ano de 2009, permitiram conhecer quais foram as causas que motivaram os afastamentos do funcionário.

Os estímulos à criação de ambientes e estilos de trabalho saudáveis devem ser incentivados. De acordo com Maslach e Leiter (1999), para que se resolva o desequilíbrio que leva ao stress entre o indivíduo e o trabalho, faz-se necessário enfocar tanto o trabalhador como o ambiente em que desenvolve suas atividades. Enfatizam também que a estrutura e o funcionamento do local de trabalho moldam a forma de interaçáo das pessoas e a forma como elas realizam seu trabalho. Quando o local de trabalho não reconhece o lado humano dessa atividade, o risco de desgaste cresce, trazendo com ele um preço bastante alto. 
Concordamos com Dejours (1993, 1994, 2003), quando afirma que trabalhar não se resume a produzir, é também viver junto. Assim, o trabalho torna-se uma grande oportunidade de aprender o respeito pelo outro, a confiança, a convivência, a solidariedade. As regras do trabalho não se limitam a regras técnicas, mas, sobretudo as sociais. Assim, investigar a organização dos ambientes e relaçóes no trabalho que geram sofrimento e doenças, deveria ser uma possibilidade de repensá-los e reorganizá-los.

\section{FROM WHAT THEY GET SICK AND WHY UNIVERSITY WORKERS GET AWAY FROM WORKING: 2009 YEAR ANALYSIS}

ABSTRACT: It is a study, quantitative, which evaluated in 2009, the fact that they were during that period, apart from the different working employees who worked in four units of a public university in São Paulo, as well as the cause of the illness that caused this separation. The working framework, involving the workplace, duties performed and clearance period, it can be said that men and women who have been away from work for a longer time, had their assignments preferably linked to repetitive services. It was determined that the prevalent morbidities related to those followed mental disorders of the musculoskeletal system and connective tissue diseases. These findings drive necessary theoretical insights about the conditions of work environments where these workers as well as the satisfaction thereof, to identify and prevent aspects that generate conflicts, pressures and suffering in the workplace, which can trigger diseases.

KEYWORDS: Work. Worker.Illness.Prevention.

\section{REFERÊNCIAS}

BRASIL. Ministério da Saúde. Doenças relacionadas ao trabalho: Manual de procedimentos para os serviços de Saúde. Brasília: Ministério da Saúde, 2001. 
BRASIL. Ministério da Saúde. Portaria no 3120/1998, de 1o de julho de 1998. Aprova a Instrução Normativa de Vigilância em Saúde do Trabalhador no SUS. Diário Oficial da Uniáo, Brasília,14 jul.1998a.

. Portaria no 3908, de 30 de outubro de 1998. Estabelece procedimentos para orientar e instrumentalizar as açóes e serviços de saúde do trabalhador no Sistema Único de Saúde (SUS). Diário Oficial da Uniáo, Brasília, n. 215, seção 1, 10 nov. 1998b.

BRASIL. Constituição (1988). Constituição da República Federativa do Brasil. Brasília: Senado Federal, 1988.

DEJOURS, C. A loucura do trabalho. 5.ed. São Paulo: Cortez, 2003.

- Psicodinâmica dotrabalho: contribuiçôes da escola dejouriana à análise da relação prazer, sofrimento, trabalho. São Paulo: Atlas, 1994.

. Uma nova visão do sofrimento humano nas organizaçóes. São Paulo: Atlas, 1993.

MASLACH, C.; LEITER, M. P. Trabalho: Fonte de prazer ou desgaste? Guia para vencer o estresse na empresa. Campinas: Papirus, 1999.

PINHEIRO, D. P. N A resiliência em discussão. Psicologia em Estudo, Maringá, v.9, n.1, p.67-75, jan/fev. 2004. 


\section{ANEXO 1 - CID 10}

A - doenças infecciosas e parasitárias

$\mathrm{B}$ - infecçóes virais caracterizadas por lesão em peles e mucosas

$\mathrm{C}$ - neoplasias malignas

$\mathrm{D}$ - neoplasias benignas

E - doenças endócrinas, nutricionais e metabólicas

$\mathrm{F}$ - transtornos mentais e comportamentais

$\mathrm{G}$ - doenças do sistema nervoso

$\mathrm{H}$ - doenças do olho e anexos

I - doenças do aparelho circulatório

$\mathrm{J}$ - doenças do aparelho respiratório

$\mathrm{K}$ - doenças do aparelho digestivo

$\mathrm{L}$ - doenças da pele e tecido subcutâneo

$\mathrm{M}$ - doenças do sistema osteomuscular e tecido conjuntivo

$\mathrm{N}$ - doenças do aparelho geniturinário

$\mathrm{R}$ - sinais, sintomas e achados anormais de exame clínico e de laboratório

$S$ - lesôes, traumatismos e algumas outras consequências de causas externas

$\mathrm{T}$ - traumatismos envolvendo múltiplas regiôes do corpo

W - outras causas externas de traumatismos

$\mathrm{Z}$ - fatores influenciam o estado de saúde e o contato com os serviços de saúde 
